\title{
Case Study: Materials Selection for Replacing A Fractured Pendulum Holder of Charpy Impact Testing Machine Hung-Ta 8041a Type Based on the Working Load
}

\author{
Winarto, Eddy Widiyono, Nur Husodo, Atria Pradityana, and Subowo
}

\begin{abstract}
The pendulum holder of our Charpy impact testing machine HUNG-TA 8041 A type has fractured as a result of fatigue so that, it needs a replament of this pendulum holder. In this case, we tried to select the appropriate material in order to avoid buying the new impact testing machine by repairing the fractured pendulum holder. To determine the new material, some tests have been carried out comprise of material tests using SEMEDS, and also load analysis that works to the holder according to machine design theory, and next step is doing a verification using Ansys software and the result will be used as a base in choosing the material. Based on the material test that has been held, it is known that pendulum holder material is high carbon steel with carbon content is about $0.6 \%$, and from the machine design analysis we found that the working load to the pendulum holder is $0.349 \mathrm{MPa}$, and finally from analysis using Ansys software it was found that the pendulum working load is $0.48 \mathrm{MPa}$, there is a different result as high as $37 \%$. From those series of tests and analysis, the material selected to replace the broken holder is AISI 1060 steel.
\end{abstract}

Keywords—Holder, Impact, Material, Ansys.

\section{INTRODUCTION}

The Charpy impact test, also known as the Charpy V-notch test, is a standardized high strain-rate test which determines the amount of energy absorbed by a material during fracture. This absorbed energy is a measure of a given material's notch toughness and acts as a tool to study temperature dependent ductile-brittle transition. It is widely applied in industry, since it is easy to prepare and conduct and results can be obtained quickly and cheaply.

Today it is utilized in many industries for testing materials, for example the construction of pressure vessels and bridges to determine how storms will affect the materials used [1][2].

Talukdar studied the effect of fatigue damage in En-8grade heat treated steel (annealed and hardened and tempered), under different cyclic loading properties [3]. The results indicate higher fracture toughness and impact toughness in hardened-and-tempered steel than in annealed steel. Cyclic hardening and softening occurs in both the

Winarto, Eddy Widiyono, Nur Husodo, Atria Pradityana, and Subowo are with Department of Industrial Mechanical Engineering, Institut Teknologi Sepuluh Nopember, Surabaya, 60111, Indonesia. E-mail: bowo@me.its.ac.id. hardened-and tempered as well as the annealed steel. With the increase of peak stress and number of fatigue cycles, the hardened-and-tempered steels. The results are discussed in terms of dislocations, slip bands, and their density, microstructure, and fracture morphology.

Fernandez-Cantelia studied the dynamic behavior of three different fiber fabric composite laminates by testing notched specimens in an instrumented Charpy machine [4]. The registered impact force and displacement at the specimen hammer contact point were used to evaluate Mode-I fracture energy and dynamic fracture toughness. The changes in fracture toughness due to impact velocity, crack size and stacking sequence of the specimen were investigated with different degrees of aging conditions. Aging was found to significantly affect the dynamic fracture toughness, but had less effect on the static fracture toughness.

Bimal and Surendra evaluated that Charpy V-notch impact toughness of $600 \mathrm{MPa}$ yield stress TMT rebars alloyed with copper, phosphorus, chromium and molybdenum [1]. Subsized Charpy specimens were machined from the rebar keeping the tempered martensite rim intact. The copperphosphorus rebars showed toughness of $35 \mathrm{~J}$ at room temperature. The toughness of coppermolybdenum and copper-chromium rebars was $52 \mathrm{~J}$. The lower toughness of phosphorus steel was attributed to solid solution strengthening and segregation of phosphorus to grain boundaries. Due to superior corrosion resistance, copperphosphorus TMT rebar was a candidate material in the construction sector.

Mustafa investigated the impact fatigue properties of unidirectional carbon fibre reinforced polyetherimide (PEI) composites [5]. Low velocity repeated impacts were performed by using pendulum type instrumented impact tester (Ceast, Resil 25) at energy levels ranging 0.54-0.94 J. Samples were prepared according to ISO 180 and subjected to repeat low velocity impacts up to fracture by the hammer. Results of repeated impact study were reported in terms of peak load (Fmax), absorbed energy (Emax) and number of repeated impacts. An analytical model to describe the life time of composite materials subjected to repeated impact loadings was presented.

Ajit investigated the impact resistance of silicon ( $\mathrm{Si}$ )containing modified $9 \mathrm{Cr}-1 \mathrm{Mo}$ steels within a temperature 
International Conference on Engineering, Advance Science and Industrial Application (ICETESIA) 2018

September 6-7 2018, Institut Teknologi Sepuluh Nopember, Surabaya, Indonesia

regime of -40 to $44^{\circ} \mathrm{C}$ using the Charpy method [2]. The results indicated that the energies absorbed in fracturing the tested specimens were substantially lower at temperatures of $-40,25$, and $75^{\circ} \mathrm{C}$ compared to those at elevated temperatures. Lower impact energies and higher Ductile-toBrittle Transition Temperatures (DBTTs) were observed with the steels containing 1.5 and 1.9 wt.\% Si. The steels containing higher Si levels exhibited both ductile and brittle failures at elevated temperatures. However, at lower temperatures, brittle failures characterized by cleavage and inter granular cracking were observed for all four tested materials.

Chandrashekhar et al. has done modeling and analysis of hammer of impact testing machine, that was planned for the hammer of impact machine and also trying to find out the failures in the hammer [6]. If possible, by changing design of hammer of impact testing machine, weight and cost can be reduced.

In this impact test, a standard impact testing machine is needed in order to assure that the test will be well done. If the holder has malfunction, the test will not run correctly and of course the result will be inaccurate.

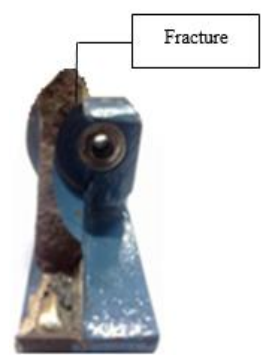

Figure 1. Fractured pendulum holder.

To analyze the pendulum holder working load, it needs some mathematical equation as follows [3]:

Torsion and power

$$
\begin{aligned}
& \mathrm{T}=9549 \frac{\boldsymbol{P}}{\boldsymbol{n}} \\
& \text { where: } \\
& \mathrm{T}=\text { Torsion }[\mathrm{N} . \mathrm{m}] \\
& \mathrm{P}=\text { power }[\mathrm{HP}] \\
& \mathrm{n}=\text { rotation per minute }[\mathrm{rpm}]
\end{aligned}
$$

Centripetal force $\left(F_{S}\right)$ of the pendulum

$$
F_{(c f)}=m_{p} \frac{V_{p}^{2}}{r_{p}}
$$

where:

$F_{(c f)}=$ centripetal force $[\mathrm{N}]$

$m_{p}=$ pendulum mass $[\mathrm{kg}]$

$V_{p} \quad=$ velocity of the pendulum $[\mathrm{m} / \mathrm{sec}]$

$\boldsymbol{r}_{\boldsymbol{p}} \quad=$ pendulum arm length $[\mathrm{m}]$

Tensile stress to the holder can be formulated as,

$$
\sigma_{t}=\frac{F}{A}
$$

$\mathrm{F}=$ working force $[\mathrm{N}]$ )

$\mathrm{A}=$ cross sectional area $\left[\mathrm{m}^{2}\right]$

In order to assure the safety of the design, we have to take into acount the safety factor $\boldsymbol{s}_{\mathbf{f}}$ so

Tensile stress

$$
\begin{aligned}
& \sigma_{t} \leq\left|\sigma_{t}\right| \\
& \frac{F}{A} \leq \frac{\sigma_{y p}}{s_{f}}
\end{aligned}
$$

Compression stress

$$
\begin{aligned}
& \sigma_{c} \leq\left|\sigma_{c}\right| \\
& \frac{F}{A} \leq \frac{\sigma_{y p}}{s_{f}} \\
& \text { where: } \quad \sigma_{y p}=\text { yield point stress }
\end{aligned}
$$

Stress distribution can be found so that in calculating the stress, it is recommended to use the following safety factor:
a. a. $s_{\mathrm{f}}=1$ for constant torsion load
b. $s_{\mathrm{f}}=2.5$ for low impact load
c. $s_{\mathrm{f}}=4.5$ for high impact and especially cyclic load.

The pendulum holder of our Charpy impact testing machine HUNG-TA 8041A type has fractured as a result of fatigue so that, it needs a replament of this pendulum holder. In this case, we tried to select the appropriate material in order to avoid buying the new impact testing machine by repairing the fractured pendulum holder.

\section{METHODOLOGY}

Once the exact holder dimension can be found from the measurement, the material test is conducted by using SEMEDS so that, the replacing materials for the holder can be determined.

The next steps are checking the load that works to the pendulum holder which comprise of working load analysis from the machine design theory and and another load analysis resulted by the use of Ansys software.

The final step is judging the appropriate material for the pendulum holder that is the load that works to the pendulum holder not exceed the allowed working load of the material

\section{DISCUSSION}

\section{A. Material Testing by SEM-EDS of the Pendulum Holder Material}

From the material testing by SEM-EDS, the composition of the holder materials are as follows:

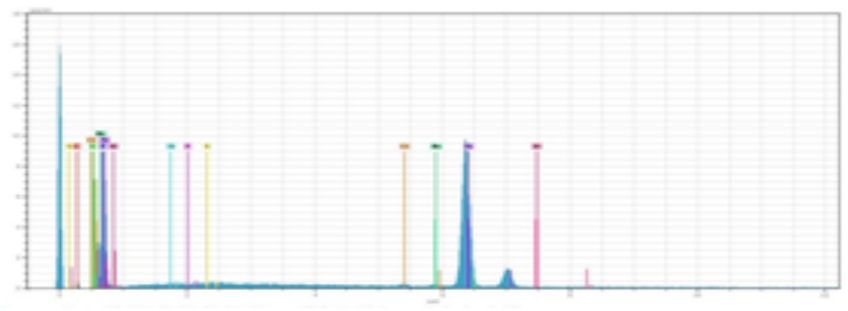

Figure 2. Material composition from SEM-EDS element testing. where: 
The accompanying result of the SEM-EDS element testing is the chemical camposition of the holder material that presented in the Table 1.

TABLE 1.

CHEMICAL COMPOSITION

\begin{tabular}{lllrrrc}
\hline \hline El & AN & Series & $\begin{array}{c}\text { unn.C } \\
\text { [wt.\%] }\end{array}$ & $\begin{array}{c}\text { norm. C } \\
\text { [wt.\%] }\end{array}$ & $\begin{array}{r}\text { atom. C } \\
\text { [at,\%] }\end{array}$ & $\begin{array}{c}\text { Error } \\
{[\%]}\end{array}$ \\
\hline $\mathrm{C}$ & 6 & K-series & 0.60 & 0.60 & 2.44 & 0.2 \\
$\mathrm{O}$ & 8 & K-series & 0.00 & 0.00 & 0.00 & 0.0 \\
$\mathrm{~F}$ & 9 & K-series & 5.79 & 5.84 & 15.04 & 1.7 \\
$\mathrm{Si}$ & 14 & K-series & 0.24 & 0.24 & 0.42 & 0.0 \\
$\mathrm{P}$ & 15 & K-series & 0.19 & 0.19 & 0.31 & 0.0 \\
$\mathrm{~S}$ & 16 & K-series & 0.36 & 0.37 & 0.56 & 0.0 \\
$\mathrm{Cr}$ & 24 & K-series & 0.74 & 0.75 & 0.70 & 0.1 \\
$\mathrm{Mn}$ & 25 & K-series & 0.70 & 0.70 & 0.63 & 0.1 \\
$\mathrm{Fe}$ & 26 & K-series & 89.67 & 90.45 & 79.19 & 2.4 \\
$\mathrm{Ni}$ & 28 & K-series & 0.85 & 0.86 & 0.71 & 0.1 \\
& & Total: & 99.15 & 100.00 & 100.00 & \\
\hline \hline
\end{tabular}

Based on the SEM-EDS element testing it can be found that the pendulum holder material is the carbon steel with carbon content $0.6 \%$ which turn into a forecast that the material for pendulum holder is AISI 1060 Steel with the chemical composition is as follows:

TABLE 2.

CHEMICAL COMPOSITION OF AISI 1060 STEEL (WWW. AZOM.COM)

\begin{tabular}{ccccc}
\hline \hline Fe & C & Mn & S & P \\
\hline $98.35-98.95$ & $0.60-0.90$ & $0.55-0.660$ & $\leq 0.050$ & $\leq 0.040$ \\
\hline \hline
\end{tabular}

With the mechanical properties as follows:

TABLE 3.

MECHANICAL PROPERTIES OF AISI 1060 STEEL (WWW. AZOM.COM)

\begin{tabular}{lc}
\hline Tensile strength, ultimate & $\mathbf{6 2 0 ~ M P a}$ \\
\hline Tensile strength, yield & $485 \mathrm{MPa}$ \\
Modulus of elasticity & $150 \mathrm{GPa}$ \\
Elongation at break ( in $50 \mathrm{~mm}$ ) & $10 \%$ \\
Hardness, Brinell & 183 \\
\hline \hline
\end{tabular}

B. Calculation of Holder Working Load Using Machine Design Theory

According to the impact-testing machine.

TABLE 4.

\begin{tabular}{ccccc}
\multicolumn{5}{c}{ MOTOR SPECIFICATION } \\
\hline \hline Remarks & Voltage & $\boldsymbol{n}$ & $\boldsymbol{P}$ & Ratio \\
\hline Motor & $110 \mathrm{~V}$ & 1720 & $1 \mathrm{HP}$ & $1: 25$ \\
\hline \hline
\end{tabular}

Torsion output

$$
\begin{aligned}
T=9549 \frac{P}{n} \quad ; \quad \text { Rotation output } & =\mathrm{n} \times \text { Ratio } \\
& =1720 \times 1 / 25 \\
& =68.8 \mathrm{rpm}
\end{aligned}
$$$$
=9549 \frac{1 \mathrm{HP}}{68,8}
$$

1. Centripetal force Pendulum to the holder

The analysis are based on the three positions of the pendulum $\left(50^{\circ}, 0^{\circ}\right.$ and $\left.-50^{\circ}\right)$ in order to know the centripetal force works to the pendulum.

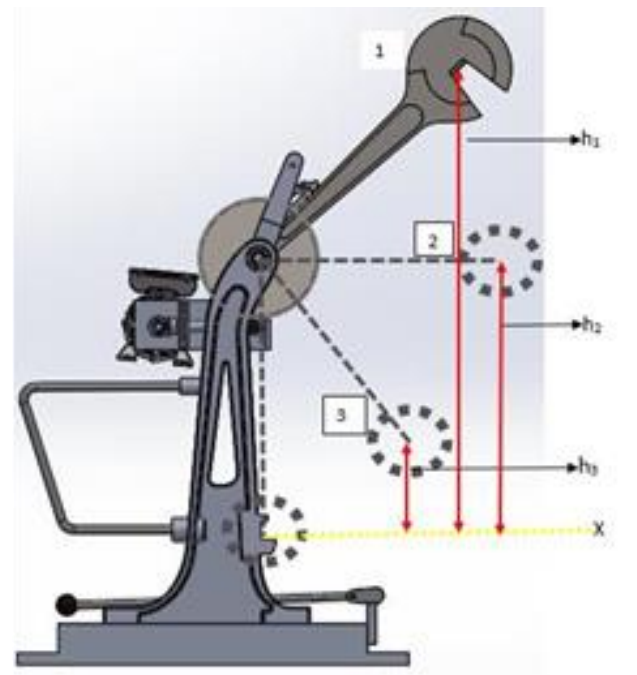

Figure 3. Pendulum position with angle $50^{\circ}, 0^{\circ}$ and $-50^{\circ}$.

where

$$
\begin{array}{ll}
h_{1} & =888,64 \mathrm{~mm}=0,899 \mathrm{~m} \\
h_{2} & =699,60 \mathrm{~mm}=0,699 \mathrm{~m} \\
h_{3} & =442,25 \mathrm{~mm}=0,442 \mathrm{~m}
\end{array}
$$

a. Centripetal force $\left(F_{\mathrm{s}}\right)$ pendulum at position $50^{\circ}$

$$
F_{(50)}=m_{p} \frac{V_{4}^{2}}{r_{p}}=302.757 \mathrm{~N}
$$

b. Centripetal force $\left(F_{S}\right)$ pendulum at position $0^{\circ}$

$$
F_{(0)}=m_{p} \frac{V_{2}^{2}}{r_{p}}=67.363 \mathrm{~N}
$$

c. Centripetal force $\left(F_{S}\right)$ pendulum at position $-50^{\circ}$

$$
F_{(-50)}=m_{p} \frac{V_{2}^{2}}{r_{p}}=157.690 \mathrm{~N}
$$

As the reference in calculating the holder working load, the position at angle $50^{\circ}$ is selected because in this position, holder is used as a hook for the pendulum before the pendulum released to hit the impact testing specimen.

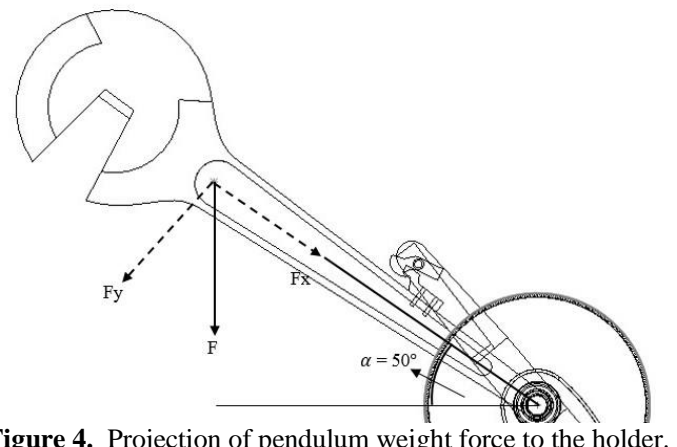

Figure 4. Projection of pendulum weight force to the holder.

Weight force is the weight of the pendulum which will be projected to the holder.

$$
\begin{aligned}
& F=13,7 \mathrm{~kg} \times 10 \mathrm{~m} / \mathrm{s}^{2}=137 \mathrm{~N} \\
& F_{\mathrm{y}}=F \mathrm{x} \cos \alpha \\
& =137 \mathrm{~N} x \cos 50^{\circ}=88.06 \mathrm{~N} \\
& F_{\mathrm{x}}=F \mathrm{x} \sin \alpha \\
& =137 \mathrm{~N} x \sin 50^{\circ}=104.948 \mathrm{~N}
\end{aligned}
$$


International Conference on Engineering, Advance Science and Industrial Application (ICETESIA) 2018

September 6-7 2018, Institut Teknologi Sepuluh Nopember, Surabaya, Indonesia

\section{Forces at the holder}

After pendulum's weight force $\mathrm{F}$ being projected to the holder, it is known that the holder is facing tensile force.

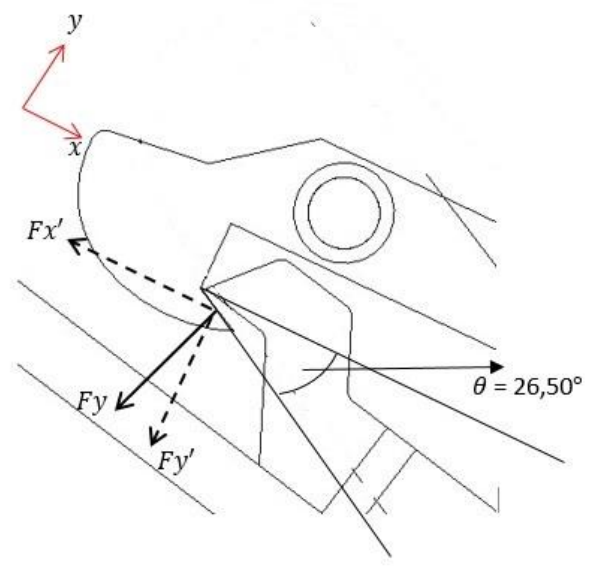

Figure 5. Forces work to the holder.

$$
\begin{aligned}
F_{\mathrm{y}}{ }^{\prime} & =F_{\mathrm{y}} \times \sin \theta^{\circ} \\
& =88.06 \mathrm{~N} \times \sin 26,50^{\circ}=39.292 \mathrm{~N} \\
F_{\mathrm{x}}{ }^{\prime} & =F_{\mathrm{y}} \times \cos \theta^{\circ} \\
& =88.06 \mathrm{~N} \times \cos 26,50^{\circ}=78.808 \mathrm{~N} \\
\mathrm{~A} & =l \times w \\
\mathrm{~A} & =0,015 \mathrm{~m} \times 0.0075 \mathrm{~m} \\
\mathrm{~A} & =1.125 \times 10^{-4} \mathrm{~m}^{2}
\end{aligned}
$$

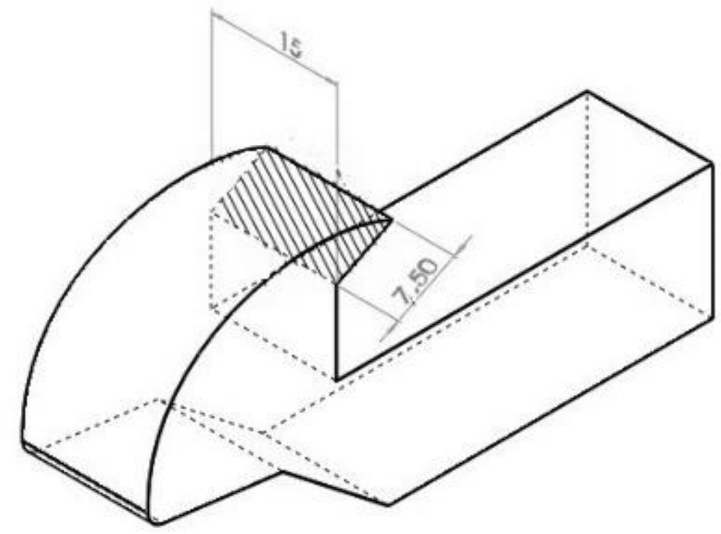

Figure 6. Smallest area exposed to the load.

Based on the calculation of the force at holder above, therefore, according to machine design theory:

$$
\begin{aligned}
\sigma_{t} & =\frac{F y^{\prime}}{A} \\
\sigma_{t} & =\frac{39,292 \mathrm{~N}}{1,125 \times 10^{-4} m^{2}} \\
\sigma_{\mathrm{t}} & =0.349 \mathrm{MPa} .
\end{aligned}
$$

\section{Calculation of Holder Working Load Using Ansys} Software

Before applying the load, it is worth to edit the material which is AISI 1060 seel, in order to garranty an accurate analysis. Once the material editing finished, the load is applied to the selected area.

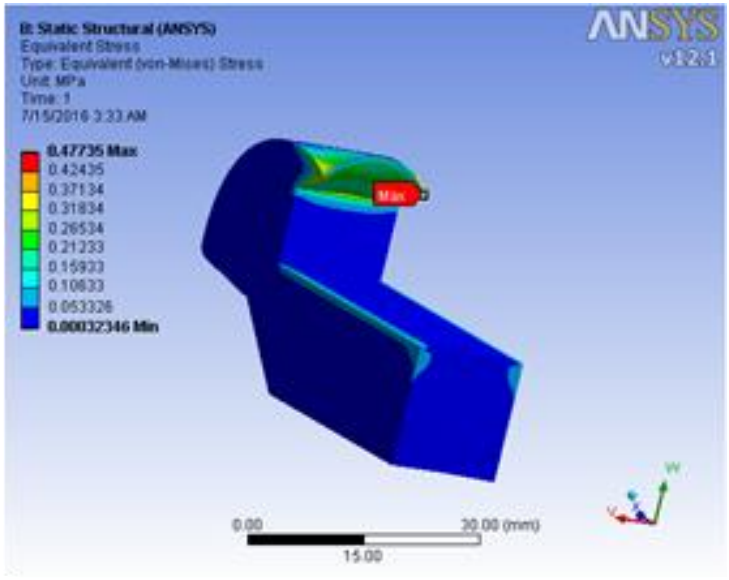

Figure 7. Analysis result from Ansys.

From calculation using Ansys, resulting a tensile stress in the order of $0.48 \mathrm{MPa}$, there is a different result about $37 \%$ which caused by the consideration taken in the machine design theory that is average load while in the Ansys software the load is maximum at the stress concentration.

Due to the maximum stress emerging from maximum load, the AISI 1060 steel with $\sigma_{\text {yp }}=485 \mathrm{MPa}$ is selected as the material for replacing the broken pendulum holder.

Tensile stress

$$
\begin{aligned}
& \sigma_{t} \leq \frac{\left[\sigma_{y p}\right]}{s f} \\
& 0.48 \mathrm{MPa} \leq \frac{485 \mathrm{MPa}}{4.5}
\end{aligned}
$$

From maximum stress analysis then compared with material maximum allowable stress, it is proven that the AISI 1060 steel could be used as material to replace the fractured pendulum holder.

\section{CONCLUSION}

Material used in existing pendulum holder is high carbon steel with carbon content about $1.91 \% \mathrm{C}$. There is a different result of tensile stress about $37 \%$ that is $0.48 \mathrm{MPa}$ from Ansys analysis and $0.349 \mathrm{MPa}$ from machine design analysis.The selected material for the replacement of the broken pendulum holder is AISI 1060 steel.The replacing material has better mechanical properties than existing material used for pendulum holder.

\section{REFERENCES}

B. K. Panigrahi and S. K. Jain, "Impact Toughness of High Strength Low Alloy TMT Reinforcement Ribbed Bar," Bull. Mater. Sci, vol. 25, no. 4, pp. 319-324, 2002.

[2] A. Roy, P. Kumar, and D. Maitra, "The Effect of Silicon Content on Impact Oughness of T91 Grade Steels," J. Mater. Eng. Perform., vol. 37, pp. 431-437, 2008.

[3] A. D. Deutchman and et al, Machine Design, Teory and Practice. New York: Macmillan Publishing Co, 1983.

[4] Fernandez-Cantelia, A. Arguellesa, J. Vinaa, M. S. Ramulub, and A. Kobayashib, "Dynamic Fracture Toughness Measurements in Composites by Instrumented Charpy Testing: Influence of Aging," Compos. Sci. Technol., vol. 62, pp. 1315-1325, 2002. 
[5] M. O. Bora, O. Coban, T. Sinmazcelic, I. Curgul, and V. Gunay, "On the Life Time Prediction of Repeatedly Impacted Thermoplastic Matrix Composites," Mater. Des., vol. 30, pp. 143-153, 2008.
[6]

C. J. Shende, A. R. Sahu, and A. V Deshmukh, "Modeling and analysis of hammer of Impact testing machine: a review," IJMERR, vol. 4, no. 1, 2015. 